\title{
Atrial natriuretic factor in hydrops fetalis caused by $\mathrm{Rh}$ isoimmunisation
}

\author{
F R Moya, P A T Grannum, L Riddick, J A Robert, J Pinheiro
}

\begin{abstract}
Plasma concentrations of atrial natriuretic factor were determined by radioimmunoassay in 16 human fetuses of between 19 and 38 weeks' gestation. Fifteen fetuses had varying degrees of anaemia as a result of $R h$ isoimmunisation, and one fetus was normal. Eight fetuses had ultrasonographic evidence of severe hydrops fetalis and an additional three fetuses had mild hydrops. Severely hydropic fetuses were more anaemic and immature than those with mild or no hydrops. Among fetuses from which samples were taken before in utero transfusion, concentrations of atrial natriuretic factor were higher in those with severe hydrops than in the other groups. An inverse relationship between the haemoglobin concentration and that of atrial natriuretic factor was found. In four fetuses in which severe hydrops resolved after intravascular transfusions in utero, there were significant decreases in plasma atrial natriuretic factor concentrations; in the fifth fetus the decrease was less pronounced.

Raised concentrations of atrial natriuretic factor in fetuses with severe anaemia and hydrops may be the result of atrial natriuretic factor release induced by hypoxia.
\end{abstract}

Several investigators have shown that human and animal fetuses synthesise and secrete atrial natriuretic factor into the circulation in response to various stimuli. ${ }^{1-3}$ Receptors for atrial natriuretic factor have been found in normal human and sheep placentas, which suggests that this peptide has a role in fetal fluid and electrolyte homoeostasis. ${ }^{45}$ In sheep, concentrations of atrial natriuretic factor are higher in lamb fetuses than in the ewes, ${ }^{67}$ and non-immune fetal hydrops caused by atrial pacing increased circulating concentrations of atrial natriuretic factor. ${ }^{7}$ Robillard and Weiner recently reported that acute volume expansion in human fetuses with immune haemolytic anaemia also resulted in increased concentrations of atrial natriuretic factor. ${ }^{1}$ In their study the highest concentration was in a fetus with severe anaemia and hydrops, and the concentrations decreased as the hydrops resolved. We have also reported similar preliminary findings. ${ }^{8}$

The objectives of this study were to determine whether human fetuses with varying degrees of hydrops fetalis and anaemia as a result of $R h$ isoimmunisation have increased concentrations of atrial natriuretic factor, and if those concentrations change after resolution of the hydrops by intravascular transfusion in utero.

\section{Material and methods}

Umbilical venous blood samples were obtained from human fetuses about to undergo intravascular exchange transfusion in utero for severe anaemia caused by $R h$ isoimmunisation. This was done using an ultrasound guided percutaneous needle as previously described. ${ }^{9}$ All samples were taken before the start of the transfusion. Packed cell volume and haemoglobin concentration were measured with an automated cell counter.

Blood samples for plasma atrial natriuretic factor concentrations were collected in polypropylene tubes with heparin $(1000 \mathrm{U} / \mathrm{ml})$ and aprotinin $(20 \mathrm{KIU} / \mathrm{ml})$. After centrifugation plasma samples were stored at $-80^{\circ} \mathrm{C}$ until analysis. Plasma atrial natriuretic factor concentrations were measured by radioimmunoassay (Peninsula Laboratories) using a previously described method. ${ }^{10}$ The interassay variability was $12 \cdot 7 \%$ and intra-assay variation $6 \cdot 1 \%$. The recovery in all assays was over $80 \%$.

Assessment of gestational age was based on last menstrual period and early ultrasound examination. Hydrops fetalis was diagnosed by ultrasound and was graded as follows: (i) absent, no evidence of ascites, pleural or pericardial effusion, or subcutaneous oedema; (ii) mild, a small amount of fluid in only one place (usually ascites); and (iii) severe, large amount of fluid in two or more places.

Statistical analysis was by one way and repeated measures analysis of variance (ANOVA), the Mann-Whitney U test and linear regression. When the data were skewed, they were analysed after logarithmic transformation. A probability of $<0.05$ was considered significant. All values are expressed as mean (SD).

\section{Results}

The study population comprised 15 fetuses with $\mathrm{Rh}$ isoimmunisation and one normal fetus who had samples taken at 38 weeks' gestation for determination of platelet count because of maternal immune thrombocytopenia. This fetus was normal on physical examination, and had a normal platelet count at delivery; the data were used not as a control but rather as an approximation of atrial natriuretic factor concentrations associated with normal haemoglobin concentrations. Blood was obtained from nine fetuses before they had received any transfusion in utero, whereas the other seven had had one or
New Orleans, LA 70112 USA

Accepted 14 February 1990 
Mean (SD) gestational ages and laboratory values in study group

\begin{tabular}{|c|c|c|c|c|}
\hline & \multirow{2}{*}{$\begin{array}{l}\text { Fetuses without } \\
\text { hydrops }(n=5)\end{array}$} & \multicolumn{2}{|c|}{ Fetuses with hydrops } & \multirow{2}{*}{${ }_{\text {Value }}^{*}$} \\
\hline & & $\begin{array}{l}\text { Mild } \\
(n=3)\end{array}$ & $\begin{array}{l}\text { Severe } \\
(n=8)\end{array}$ & \\
\hline $\begin{array}{l}\text { Gestational age (weeks) } \\
\text { Packed cell volume } \\
\text { Haemoglobin }(\mathrm{g} / \mathrm{l}) \\
\text { Atrial natriuretic factor }(\mathrm{pg} / \mathrm{ml})\end{array}$ & $\begin{array}{l}33(3) \\
0 \cdot 27(0 \cdot 11) \\
89(35) \\
73 \cdot 9(39 \cdot 1)\end{array}$ & $\begin{array}{l}31(3) \\
0 \cdot 20(0 \cdot 038) \\
64(16) \\
75 \cdot 4(42 \cdot 6)\end{array}$ & $\begin{array}{l}25(4) \\
0 \cdot 12(0 \cdot 056) \\
39(19) \\
576 \cdot 5(931 \cdot 8)\end{array}$ & $\begin{array}{c}<0.01 \\
<0.02 \\
<0.02 \\
0.1\end{array}$ \\
\hline
\end{tabular}

*Those with severe hydrops compared with the other two groups by ANOVA.

more transfusions in the weeks before samples were taken.

Eleven fetuses had ultrasonographic evidence of hydrops, and in eight of them it was severe (table). The remaining fetuses had no evidence of hydrops. Those with mild or no hydrops were more mature than those in which it was severe $(p<0.01$ by one way ANOVA). All fetuses with $R h$ isoimmunisation had packed cell volumes of less than 0.34 and haemoglobin concentrations below $110 \mathrm{~g} / \mathrm{l}$. Those fetuses with evidence of severe hydrops were significantly more anaemic than those in the other groups $(p<0.01$, one way ANOVA). Most fetuses with severe hydrops had higher concentrations of atrial natriuretic factor than fetuses with either no or mild hydrops, but because of the large variability this difference was not significant ( $p=0 \cdot 1$, Mann-Whitney test). When only the atrial natriuretic factor concentrations of fetuses from whom samples were taken before they received any transfusion in utero were analysed, however, those with severe hydrops $(n=6)$ had significantly higher concentrations $(755 \cdot 2(1030 \cdot 6) \mathrm{pg} / \mathrm{ml}$, range $126-2796)$ than fetuses with no or mild $(n=3)$ hydrops $(70.9(45.8) \mathrm{pg} / \mathrm{ml}$, range 39.9-123.6) $(\mathrm{p}<0.05$, Mann-Whitney U test).

An inverse relationship was found between haemoglobin and atrial natriuretic factor concentrations by using linear regression after logarithmic transformation $(y=2 \cdot 68-9 \cdot 85 e-2 x$, $\mathrm{p}<\mathrm{f.02}$ ) (fig 1). This association was also present when the analysis included only atrial natriuretic factor concentrations in samples taken before exchange transfusion in utero $\left(y=2 \cdot 88-9 \cdot 58 \mathrm{e}-2 \mathrm{x}, \mathrm{r}^{2}=0.51, \mathrm{p}<0.05\right)$.

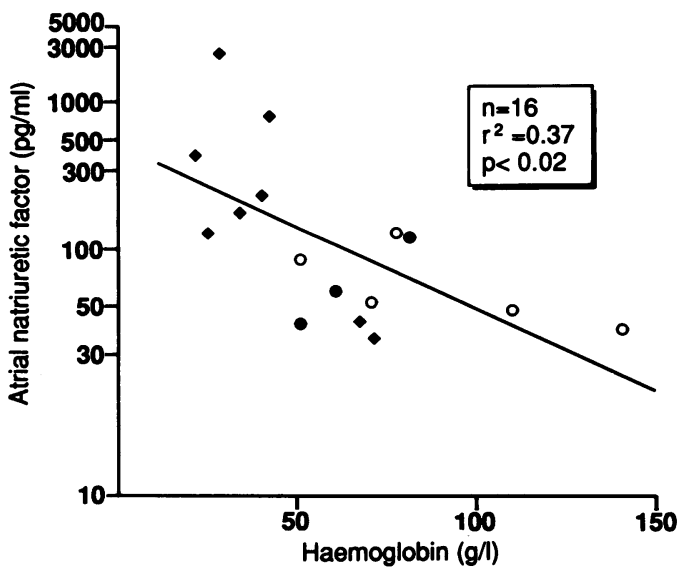

Figure 1 Relationship between haemoglobin concentration and plasma atrial natriuretic factor in all fetuses. No hydrops (○), mild hydrops ( ), and severe hydrops (৩). The vertical axis represents actual values plotted on a semilogarithmic scale.

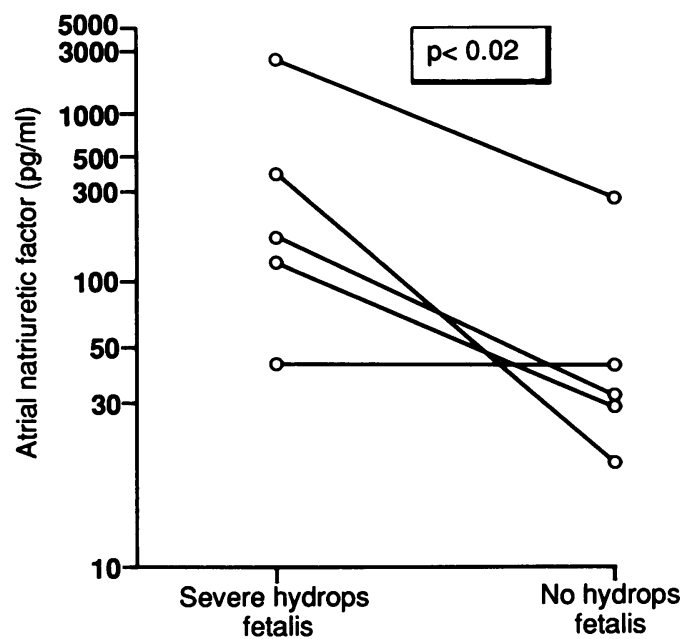

Figure 2 Plasma atrial natriuretic factor in fetuses sampled sequentially during severe hydrops and after complete resolution. The vertical axis represents actual values plotted on a semilogarithmic scale.

Five fetuses with severe hydrops were followed up serially. All showed complete resolution of both hydrops and severe anaemia after between two and five exchange transfusions in utero. In these fetuses the haemoglobin concentration increased from 34 (19) to 84 (13) $\mathrm{g} / 1$ ( $\mathrm{p}<0.005$, repeated measures ANOVA). As the signs of hydrops disappeared, there was a significant decrease in concentrations of atrial natriuretic factor $(\mathrm{p}<0.02$ by repeated measures ANOVA, fig 2).

\section{Discussion}

Immunoreactive atrial natriuretic factor has been found in the atria of human and rat fetuses early in gestation. ${ }^{11} 12$ This study, in common with several others, ${ }^{1} 1314$ has shown that human fetuses under normal or pathological conditions have a wide range of circulating atrial natriuretic factor concentrations. Animal and human fetuses have higher concentrations of atrial natriuretic factor than their mothers. ${ }^{25} 1214$ Although atrial natriuretic factor may cross the placenta, ${ }^{2}$ the small increases in maternal concentrations during pregnancy do not explain the pronounced increases that we found in fetuses with hydrops. ${ }^{15}$ Most evidence suggests that the placenta is not an important site of atrial natriuretic factor degradation, 6714 but arteriovenous differences in umbilical cord blood atrial natriuretic factor concentrations have been reported. ${ }^{12}$ Kojima et al reported mean (SD) normal cord blood atrial natriuretic factor values of $61.3(22.5) \mathrm{pg} / \mathrm{ml},{ }^{17}$ which are lower than those found by Yamaji et al, of 165 
(27) $\mathrm{pg} / \mathrm{ml} .{ }^{13}$ Normal human fetuses studied by Robillard and Weiner between 22-26 weeks' gestation had mean (SEM) plasma atrial natriuretic factor values of 90 (22) $\mathrm{pg} / \mathrm{ml} .^{1}$ No changes in the concentration of atrial natriuretic factor with advancing gestational age have been reported. ${ }^{14}$ Our study group included only one normal fetus, but the circulating atrial natriuretic factor concentrations in this and other fetuses with mild anaemia and no evidence of hydrops were well within this range, suggesting that mild decreases in fetal haemoglobin concentrations are not associated with pronounced increases in circulating atrial natriuretic factor. ${ }^{18}$

Hydrops fetalis commonly occurs when the fetal haemoglobin concentration drops below $60-70 \mathrm{~g} / 1$ as in our study, ${ }^{19}$ but the hydrops can be reversed with intravascular intrauterine transfusions, which raise fetal haemoglobin concentrations. ${ }^{9}$ In $\mathrm{Rh}$ isoimmunisation fetal oedema results from the extensive erythropoiesis in the fetal liver that disrupts the portal circulation and impairs albumin synthesis, 920 and perhaps also from the cardiovascular adaptations that are also seen in anaemic fetuses. $^{21}$ Our data show that fetuses with severe hydrops had high atrial natriuretic factor concentrations and were also significantly more anaemic than those fetuses with either mild or no hydrops. In addition, an inverse relationship was found between the haemoglobin and atrial natriuretic factor concentrations.

Several factors may explain our findings. Firstly, as $\mathbf{R h}$ isoimmunised fetuses become progressively more anaemic, their oxygen content is appreciably reduced. Haemoglobin concentrations of less than $40 \mathrm{~g} / \mathrm{l}$ may lead to tissue hypoxia as measured by increased lactate concentration in the fetal circulation. ${ }^{22}$ Hypoxia may then result in myocardial dysfunction and increases in umbilical venous pressure, with subsequent release of atrial natriuretic factor. ${ }^{18}$ Although we did not measure blood gases or lactate, all our fetuses with severe hydrops and high atrial natriuretic factor concentrations had haemoglobin concentrations associated with tissue hypoxia. ${ }^{22}$ It is likely that the tissue hypoxia in severely anaemic fetuses results more from decreased oxygen content than from lower oxygen tensions (hypoxaemia); fetuses with immune haemolytic anaemia and hydrops have similar oxygen tensions to control fetuses. ${ }^{1}$ In sheep fetuses acute hypoxia produced by infusion of carbon dioxide to the maternal trachea is a potent stimulus for the release of atrial natriuretic factor. ${ }^{23}$ Thus it seems that tissue hypoxia resulting from either a low oxygen carrying capacity (severe anaemia) or hypoxaemia, may induce atrial natriuretic factor release. Whether one mechanism is more potent than the other, or whether chronic rather than acute changes in tissue oxygenation are responsible for atrial natriuretic factor release in $R h$ isoimmunised human fetuses is unknown.

Acute volume expansion in utero also increases circulating atrial natriuretic factor concentrations in both human and sheep fetuses. ${ }^{15}$ This is unlikely to explain our findings, as all samples were taken before the start of each procedure. Furthermore, hydropic fetuses are generally not hypervolaemic, but rather normovolaemic or hypovolaemic. ${ }^{24-26}$ Arginine vasopressin and corticosteroids may also stimulate atrial natriuretic factor secretion. ${ }^{2} 27$ Weiner recently reported lower concentrations of arginine vasopressin in anaemic fetuses requiring transfusion than in those that were not anaemic. ${ }^{18}$ This makes atrial natriuretic factor release induced by arginine vasopressin a less likely explanation of our findings. Stimulation of atrial natriuretic factor release by sympathetic hormones is also unlikely, as human fetuses with $R h$ isoimmunisation have concentrations of adrenaline and noradrenaline comparable with control values. ${ }^{14}$ There were significant reductions in plasma atrial natriuretic factor concentrations after treatment with intravascular transfusions in utero, which resulted in appreciable improvement in haemoglobin concentrations and complete resolution of the hydrops. This suggests that as oxygen delivery improves the hypoxic stimulus for atrial natriuretic factor secretion ceases. An increase in atrial natriuretic factor degradation by the kidney or other fetal organs as the fetal condition improves, however, cannot be ruled out.

In summary we have shown that human fetuses with severe degrees of anaemia and hydrops fetalis have high concentrations of atrial natriuretic factor in plasma. These high concentrations decrease as the hydrops resolves and the haemoglobin concentration increases, with treatment by intravascular transfusion in utero. The pronounced increases in the concentration of atrial natriuretic factor in fetuses with severe anaemia may be the result of a hypoxic stimulus for the release of atrial natriuretic factor.

1 Robillard J, Weiner C. Atrial natriuretic factor in the human fetus: effect of volume expansion. 7 Pediatr 1988;113:552-5. fetus: effect of volume expansion. F Pediatr 1988;113:552-5.
Wei Y, Rodi C, Day M, et al. Developmental changes in the rat atriopeptin hormonal system. F Clin Invest 1987;79:
rat rat atriopep.

3 Ross M, Ervin M, Lam R, et al. Fetal atrial natriuretic factor and arginine vasopressin responses to hyperosmolality and hypervolemia. Pediatr Res 1988;24:318-21.

4 Hatjis C, Grogan D. Atrial natriuretic peptide receptors in normal human placenta. Am $\mathcal{F}$ Obstet Gynecol 1988;159: 587-91.

5 Hatiis C, Grogan D. Atrial natriuretic peptide receptors in sheep cotyledons. Am 7 Obstet Gynecol 1988;159:1337-40.

6 Chung C, Gibbs D, Brace R. Atrial natriuretic factor in maternal and fetal sheep. Am f Physiol 1987;252:E279-82.

Nimrod C, Keane $P$, Harder J, et al. Atrial natriuretic peptide production in association with nonimmune fetal peptide production in association with nonimmune fet hydrops. Am 7 Obstet Gynecol 1988;159:625-8.

Moya F, Grannum P, Riddick L, et al. Atrial natriuretic factor in human fetuses with hydrops fetalis due to hemolytic anemia. Pediatr Res 1988;23:282A.

9 Grannum P, Copel J, Moya F, et al. The reversal of hydrops fetalis by intravascular intrauterine transfusion in severe isoimmune fetal anemia. Am F Obstet Gynecol 1988;158: 914-9.

10 Yandle T, Espiner E, Nicholls M, et al. Radioimmunoassay and characterization of atrial natriuretic peptide in human plasma. F Clin Endocrinol Metab 1986;63:72-9.

11 Morinaga $S$, Tsumuraya $M$, Nakajima $T$, et al. Immunohistochemical and immunocytochemical localization of atrial natriuretic polypeptide in human adult and fetal hearts. Acta Histochemica and Cytochemica 1985;18:605-13.

12 Dolan L, Dobrozsi D. Atrial natriuretic polypeptide in the fetal rat: ontogeny and characterization. Pediatr Res 1987;22:115-7.

13 Yamaji T, Hirai N, Ishibashi $M$, et al. Atrial natriuretic peptide in umbilical cord blood: evidence for a circulating hormone in human fetus. 7 Clin Endocrinol Metab 1986;63: 1414-7.

14 Weiner C, Robillard J. Atrial natriuretic factor, digoxin-like immunoreactive substance, norepinephrine, epinephrine, and plasma renin activity in human fetuses and their alteration by fetal disease. Am $\mathcal{F}$ Obstet Gynecol 1988;159: 1353-60. 
15 Ross M, Ervin M, Lam R, et al. Plasma atrial natriuretic peptide response to volume expansion in the ovine fetus. peptide response to volume expansion

16 Cusson J, Gutkowska J, Rey E, et al. Plasma concentration of atrial natriuretic factor in normal pregnancy. $N$ Engl $\mathcal{F}$ Med 1985;313:1230-1.

17 Kojima T, Hirata Y, Fukuda Y, et al. . Plasma atrial natriuretic peptide and spontaneous diuresis in sick neonates. Arch Dis Child 1987;62:667-70.

18 Weiner C. Nonh fusion on the human fetus. Semin Perinatol 1989;13: $338-41$.

19 Nicolaides K, Thilaganathan B, Rodeck C, et al. Erythroblastosis and reticulocytosis in anemic fetuses. Am 7 Obstet Gynecol 1988;159:1063-5.

20 Nicolaides $\mathrm{K}$, Warenski J, Rodeck C. The relationship of fetal plasma protein concentration and hemoglobin level to the development of hydrops in rhesus isoimmunization. Am F Obstet Gynecol 1985;152:341-4.

21 Rightmire D, Nicolaides K, Rodeck C, et al. Midtrimester fetal blood flow velocities in rhesus isoimmunization. Obstet Gynecol 1986;68:233-6.
22 Soothill P, Nicolaides K, Rodeck C, et al. Relationship of fetal hemoglobin and oxygen content to lactate concentration in $\mathrm{Rh}$ isoimmunized pregnancies. Obstet Gynecol tion in $\mathrm{Rh}$ isoimmunized pregnancies. Obstet Gynecol

23 Cheung C, Brace R. Fetal hypoxia elevates plasma a trial natriuretic factor concentration. Am $\mathcal{J}$ Obstet Gynecol 1988;159:1263-8.

24 Phibbs R, Johnson P, Tooley W, et al. Cardiorespiratory status of erythroblastotic newborn infants: II. Blood volume, hematocrit, and serum albumin concentration in relation to hydrops fetalis. Pediatrics 1974;53:13-23.

25 Barss V, Doubilet $P$, John-Sutton $M$, et al. Cardiac output in a fetus with erythroblastosis fetalis: assessment using pulsed doppler. Obstet Gynecol 1987;70:442-4.

26 Nicolaides K, Clewell W, Rodeck C. Measurement of human fetoplacental blood volume in erythroblastosis fetalis. $A m \mathcal{F}$ Obstet Gynecol 1987;157:50-3.

27 Garcia R, Debinski W, Gutkowska J, et al. Gluco and mineralocorticoids may regulate the natriuretic effects and the synthesis of and release of atrial natriuretic factor by the 806-14. 